\title{
Determinants of HIV Treatment Adherence in Ethnically Diverse and Economically Disadvantaged Patients in a Tertiary Hospital, Nigeria
}

\author{
Olugbenga Aremu, Ijaodola ${ }^{1 *}$, Adedayo Adeyemi ${ }^{2}$, Rasheed Bakare ${ }^{3}$, Omowumi Romoke \\ $\mathrm{Salau}^{4}$ \\ ${ }^{I}$ Prevention of Mother to Child Transmission branch, National AID and STIs Control \\ Program, Federal Ministry of Health, Nigeria \\ ${ }^{2}$ Monitoring and Evaluation Expert, Center for Infectious Research and Evaluation Abuja, \\ Nigeria \\ ${ }^{3}$ Department of Microbiology, University College Hospital, Ibadan, Nigeria \\ ${ }^{4}$ Department of Nursing Science, Obafemi Awolowo University Ile-Ife, Nigeria
}

\begin{abstract}
Antiretroviral therapy (ART) has decreased the mortality and morbidity of HIV/AIDS, and high adherence to ART (>95\%) is necessary for a good therapeutic outcome. Non-adherence can lead to drug-resistant HIV caused by failure to achieve maximal viral suppression. Little is known about adherence to ART and its determinants among ethnically diverse and economically disadvantaged patients. The purpose of the study was to identify the level of adherence and describe factors that influence ART adherence among ethnically diverse and economically disadvantaged patients. This is with a view to providing information that could help health care providers understand patient motivations for discontinuing their antiretroviral treatment and helping patients collaboratively develop treatment regimens that facilitate adherence and optimize the outcomes of HIV/AIDS therapy. A cross-sectional descriptive survey was used. Data were collected among $400 \mathrm{HIV}$-infected patients on $A R V$ who received pretreatment and ongoing adherence counseling and education since 2010 using a self-administered questionnaire. The data were analyzed using Statistical Package for Social Sciences (SPSS). Findings showed that the self-reported adherence to the specific timing for taking the medications (medication schedule) was significantly low (8.3\%). The major factors for non-adherence to medication reported in this study were being busy at work or school, forgetfulness, fasting and travelling away from home. Also, employment status was associated with poor adherence, which may be corroborated by the major reason for non-adherence (busy at work or school). This study is one of the first steps in the exploration of the relationship of factors responsible and medication adherence among HIV patients. This study used three different measures of medication adherence. These are patients' knowledge of the benefits of taking the drugs, adherence to a medication schedule, and the number of prescribed doses of medications missed. Health care providers must identify possible barriers to adherence at the earliest and provide appropriate solutions. These factors should be considered when designing and implementing adherence interventions.
\end{abstract}

Keywords: Anti-retroviral therapy, Determinants, HIV-infected patients, Treatment adherence.

\section{Introduction}

Anti-Retroviral Therapy (ART) has improved the quality of life of human immunodeficiency virus (HIV) patients worldwide [1]. A reduction in HIV-related morbidity and mortality has been recognized in countries where ART has been made widely available [1]. Acquired immune deficiency syndrome (AIDS) is now a manageable chronic illness; and to achieve

*Corresponding Author: gijaodola@gmail.com 
optimal results from ART, high levels of patient adherence to ART (at least 95\%) is essential [2].

Medication adherence is the term used to describe the extent to which a patient's behavior corresponds with the prescribed medication dosing regimen, including time, dosing, and interval of medication intake [3]. Adherence to ART is defined as the ability of HIV-infected patients to be involved in choosing, starting, managing, and maintaining a given therapeutic combination medication regimens to control HIV replication and improve immune function [4]. It involves a partnership between the patient and the health care team. Non-adherence is the term used to describe the patient's inability to take their drugs in the agreed manner.

Antiretroviral therapy has been proven to significantly reduce the viral loads of HIV patients and forms an integral part of the comprehensive approach used in curbing the AIDS epidemic [5]. While the availability of highly active antiretroviral therapy (HAART) improves the lives of HIV patients. Adherence to the antiretroviral treatment is the only way through which people living with HIV can lead a healthy life as the disease is incurable till date [6] Sub-optimal adherence to ART among patients remains a major challenge and can lead to the development of resistant strains and ultimately to regimen failure, increased morbidity and mortality $[7,8]$.

Patients make critical decisions that affect the therapeutic outcome of their disease. In this sense, patients share power with providers in the consumption process. Patients' beliefs about disease and medications may be crucial to their intentional adherence behaviors and may be very different than providers. Thus, an apparently irrational act of non-adherence from the physician's or pharmacist's point of view may be a very rational action when seen from the patient's perspective. However, very little is known about how disease severity affects perceptions of health status, perceived benefits, and perceived barriers of treatment and further affects decision-making regarding medication adherence among HIV/AIDS patients. Various factors have been identified from cross-sectional studies that can influence ART adherence in patients. [9]. These are categorized into 4 groups: patient-related, provide-related, drug or diseaserelated and environmental factors [10]. Barriers reported in both developed and developing countries included fear of disclosure, patient's ability to read and understand medication instructions, adverse medication effects, concomitant substance abuse, forgetfulness, and suspicions about treatment, self-efficacy, and complexity of treatment regimens, number of pills required, decreased quality of life, work and family responsibilities, falling asleep, and access to medication [11, 12, 13, 14]. Barriers frequently reported by persons from resourcepoor countries were issues of access, including financial constraints and a disruption in medication availability and cultural beliefs $[15$, 16, 17].

Adherence to antiretroviral therapy has been strongly correlated with HIV viral suppression, reduced rates of resistance, maintaining immune function, an increase in survival, prevents disease progression, and improved quality of life [18]. Efforts to maximize patient adherence will be crucial for the suppression of HIV replication and preventing the emergence of the drugresistant virus [19]. These include both counseling patients on medication adherence before initiating ART and the ongoing medication adherence counseling and assessment after commencing ART. Patients should know the goals of the therapy, reasons why adherence is important, what to expect, and should be helped to create plans for success.

However, medication adherence monitoring is not a routine clinical practice in many resource-limited settings. Although the abovementioned factors that influence adherence are known in general terms, reasons for ART nonadherence remain inadequately understood among the study population. It is imperative that the level adherence is assessed as well as the factors (drivers) influencing poor adherence 
among ethnically diverse and economically disadvantaged patients are identified in order to develop targeted interventions. To increase the effectiveness and minimize the costs of health care, it is important to understand patients' decision-making and the strategies that can enhance patients' medication adherence. Hence this study evaluated self-reported medication adherence and factors for non-adherence in HIVinfected patients since 2009 on ART in an HIV treatment center in Nigeria.

\section{Methods}

\section{Design}

The study adopted a descriptive crosssectional design to identify the determinants of treatment adherence in ethnically diverse and economically disadvantaged patients.

\section{Description of the Site}

This study was carried out in District Hospital, Wuse Abuja, Nigeria, a secondary public health care facility that offers comprehensive HIV care services, including antiretroviral therapy (ART). It has a 120-bed capacity and serves the people living in the Wuse district and its environs. In this hospital, HIVpositive clients identified at the HIV counselling and testing service points are enrolled into a PreART register for follow-up, and only those who meet the eligibility criteria for starting antiretroviral therapy based on the Nigeria national ART guideline are commenced on treatment. Antiretroviral drugs and a number of drugs for the treatment of opportunistic infections and other related services are fully funded by the Federal Government of Nigeria with the support of the President's Emergency Plan for AIDS Relief (PEPFAR) through US Agency for International Development (USAID) and are provided at no-cost to the patients.

\section{Sampling and Sampling Technique}

The study population included a cohort of 400 HIV infected comprised of antiretroviraltherapy-naïve adults (aged 18 years or older) patients who were enrolled and commenced antiretroviral therapy (ART) from January 1, 2010, till date of data collection completion (September 2020) in Wuse District Hospital Abuja, FCT Nigeria; and received the medication adherence intervention. The sample size was determined using Cochran's formula $\mathrm{n}$ $=\mathrm{Z}^{2} \mathrm{pq} / \mathrm{d}^{2}$. Based on a previous prevalence of $30 \%$ and $40 \%$ buffer for incomplete questionnaire and other unexpected circumstances, the calculated sample size was 400. The study employed simple random sampling. Clinic attendance for their fourweekly refill of ARVs where patients received regular health education sessions and adherence counselling support which is part of the routine care that the HIV/ART clinic provided; was monitored, and it was categorized into regular and non-regular attendance. Patients who had regular attendance were selected for the study will be selected. At the completion of the study, there was no dropout in the number of participants giving a $100 \%$ response rate.

\section{Data Collection}

Data were collected with the use of a studyspecific semi-structured 17-item questionnaire to assess self-reported adherence, reasons for missing doses, which was administered to the study participants at medications refill visits in the pharmacy. For illiterate participants, the questionnaire was administered under the supervision of the research assistants. The study participants were educated about the study, its benefits, and their informed consent obtained before the commencement of the study. The participants were assured of the confidentiality of the information. The study instrument was field-tested among HIV-positive patients who refilled their antiretroviral drugs at the ART Pharmacy in the HIV/AIDS Treatment Centre, General Hospital Maitama, Abuja.

\section{Validity and Reliability}

The face and content validity of the instrument were ensured by versatile 
independent researchers in related fields. The study instrument was field-tested among HIVpositive patients who refilled their antiretroviral drugs at the ART Pharmacy in the HIV/AIDS Treatment Centre, General Hospital Maitama, Abuja. The feedback was used to review the questionnaire by the researcher and expert colleagues for content validity, and reliability tested using the test-re-test technique. The characteristics of the hospital and participants used in the field testing were similar to the study site and sample.

\section{Procedure for Data Collection/Ethical Approval}

The study participants were educated about the study, its benefits, and their informed consent obtained before the commencement of the study. The participants were assured of the confidentiality of the information. For illiterate participants, the questionnaire was administered under the supervision of the research assistants. The feedback was used to review the questionnaire by the researcher and expert colleagues for content validity and reliability tested using the test-re-test technique. The characteristics of the hospital and participants used in the field testing were similar to the study site and sample.

Patients who met the inclusion criteria were informed by the physician, or the clinic pharmacist, about the purpose and nature of the study. Verbal information regarding the study and the patient's right to refusal were provided. Patients who agreed to participate were given the written questionnaire on which their pharmacist or physician had indicated the patient's disease stage.

The subjects were allowed to complete the survey in the clinic. The questionnaire was returned to investigators for data analysis. Hence, the physician would not see the patient's responses, and the investigators would not know the identity of the respondent, thereby ensuring anonymity.
An approval letter from the HIVAIDS division, FMOH, was obtained for the study procedures and data collection instruments. Ethical approvals were received from FCT Ethical committee, where the study center falls under, and final approval was received from the authority of the General Hospital Wuse Abuja.

\section{Data Analysis}

Statistical Package for Social Sciences (SPSS) was used for data analysis. The data file contained seventy cases that represented the usable questionnaires. The data file was meticulously checked to correct errors from data entry. Frequencies were then obtained for all study variables to double-check and clean data. Descriptive statistics such as frequency distribution, simple percentages were used. Selfreported adherence was calculated as the mean scores of patients' adherence to the specific timing for taking the medications (medication schedule) and the number of prescribed doses of medications missed. Chi-Square statistics was used to test the association of adherence with occupation and education. All reported P-values were 2-sided, and $\mathrm{P}<0.05$ was used to determine statistical significance, except where otherwise indicated.

\section{Results}

\section{Socio-demographic Characteristics of Patients}

The mean age of the 400 patients on antiretroviral treatment during the study was 38.9 years $(95 \% \mathrm{CI}, 33.9 \pm 4.3)$; and the majority $(48.0 \%)$ were between the ages of 31 to 40 years; $36.7 \%$ females; $44.7 \%$ were in a nuclear family setting; $53.3 \%$ had secondary education, and $52.7 \%$ were self-employed. Details of the socio-demographic characteristics were presented in Table 1 .

\section{Medication Adherence}

Self-reported adherence was calculated as the mean scores of patients' knowledge of the benefits of taking the drugs, adherence to the 
specific timing for taking the medications (medication schedule), and the number of prescribed doses of medications missed. Although, all the participants reported being counseled on the benefits of ART and medication adherence, including how to use their medications before commencing ART. The self-reported adherence to the specific timing for taking the medications (medication schedule) was $8.3 \%$. The self-reported adherence to the prescribed doses of medications extrapolated by the response to taking drug yesterday irrespective of the specific timing of the dosing was $400(100 \%)$. Of the 400 participants, 380 $(95.0 \%)$ reported knowing the benefits of antiretroviral therapy, 13 (3.3\%) reported not knowing the benefits of ART, while 93(23.3\%) respond neutrally. On assessing the participants' knowledge of the benefits of ART, the majority of the participants, 293 (73.3\%), who reported knowing the benefits of ART responded correctly that it causes suppression of the virus, improvement of body's immune system, prolongation life and improvement of quality of life; 93 (23.3\%) did not respond at all, while 13 (3.3\%) responded incorrectly that ART is a cure for HIV. The majority of the participants acknowledged being provided information that ARV drugs resistance could result from nonadherence to medication but dealing with the side effect of HIV medication can be stressful, with 133 (33.3\%) reported agreeing (Table 2).

\section{Reasons for Adherence to Medication}

Table 3 shows the responses to the reasons for adherence with the percentage agreeing recorded. Travelling or leave home is a major factor in non-adherence to medication, with $56.7 \%$ agreeing to the fact that they forgot to bring along their drugs when they travelled or leave home. But it is a difficult to adherence to medication every day, with $66.7 \%$ reported that taking drugs every day is a real inconvenience and it is a form of hassle. The good news is that $95.0 \%$ agree that by staying on medication, they can prevent from getting sick. (Table 3 )

\section{Discussion}

Adherence to effective antiretroviral therapy has been strongly correlated with HIV viral suppression, reduced rates of resistance, an increase in survival, and improved quality of life. Adherence is the cornerstone to achieving the optimal goals of ART, and it poses a great threat to treatment success [6]. In this study, the mean self-reported adherence of ART was somewhat lower than what was reported in other studies conducted in similar settings in Africa but was slightly higher than self-reported adherence reported among ART patients in a study conducted in a similar HIV treatment center in Nigeria [20].

Nevertheless, the majority of the study participants reported over $80 \%$ adherence in the last one month prior to the study compared to these previous studies,[20] but the adherence rate required for antiretroviral therapy to achieve optimal long-term benefits is more than $95 \%$. Though the study reported a high level of knowledge about the benefits of ART and consequences of non-adherence among the study participants, the educational status of the patients was not associated with poor adherence, and this is consistent with a previous study in Nigeria.[20] The study also reported that good interpersonal relationships existed between the healthcare providers and the patients, and this can be very vital in achieving a good knowledge of ART, improving patients' self-efficacy and confidence in the healthcare system, among other benefits [21].

Achieving this high level of knowledge can be attributed to the good interpersonal relationship, pretreatment, and ongoing adherence counselling and education, which should be sustained for the optimal goal of ART [22]. Patients' medication adherence may also be influenced by their disease experiences. However, very little is known about how disease severity affects patients' beliefs about disease and medications and patients' medication-taking behaviors. 
Perceived susceptibility and severity of the disease and perceived benefits and barriers of the treatment are related to similarly worded questions about the risks of non-adherence and benefits of adherence. This leads to a possible explanation that the degree to which a patient feels threatened by an aggravation of HIV infection is conditional upon whether or not they take their medications. Perceived susceptibility may be highly correlated with the perceived effectiveness (i.e., perceived benefit) of the treatment. For example, a patient who believes that his medications are highly effective is more likely to believe that he is at lower risk of complications as long as he takes his medications as prescribed and that he is at higher risk if he does not take his medications as prescribed. Inconsistent with the literature, selfreported medication adherence was quite high in our study patients: $100 \%$ had perfect adherence during the past day. Results also revealed that some patients $(6.7 \%)$ purposefully stopped taking their HIV medications and the most common reason for intentional non-adherence was the intolerable side effects of the medication.

The advent of highly active antiretroviral therapy (HAART) means that more HIV patients need to take multiple medications for longer periods [3, 27]. But with the introduction of a combination regimen, it is expected this should improve adherence. In addition, many antiretroviral may have adverse effects, rigorous dosage and administration requirements, be associated with numerous drug interactions [24, 25]. Since symptoms can vary greatly in frequency and severity among HIV patients [23], there is likely to be considerable variability amongst HIV patients' perceptions of disease severity and progression as well as perceived benefits. Medication adherence increased as patients' disease severity increased when regimen complexity was controlled. The trend was more significant between asymptomatic patients (stage A) and symptomatic patients (stage B and C). Although one might expect less adherence in patients with more advanced HIV disease because of their increased medication needs and decreased level of physical functioning, this is often not the case. Patients who have experienced more disease symptoms are likely to have higher medication adherence. They may feel a higher risk of complications or have more experience in coping with the barriers of the treatment (e.g., side effects) compared to patients in the early stages of the disease.

Regimen complexity was found not a significant predictor of medication adherence. However, many studies have indicated that medication adherence is strongly associated with regimen complexity [26, 27, 28].

In this study, regimen complexity was calculated based on the number of daily doses. Complexity may actually be influenced by other issues, such as the timing of the doses. For example, having to take five medications that are all taken at the same dosing interval (e.g., three times a day) may be easier than taking one medication twice daily, along with another medication dosed three times a day and a third drug dosed four times a day. Finally, all demographic characteristics of the patients (age, race, gender, income, education) were not significant predictors of adherence.

\section{Conclusion}

The study reported a relatively poor medication adherence level despite the adherence intervention, compared to the desired adherence level of $>95 \%$ required to achieve optimal long-term benefits of ART. The employment status of the patients was associated with poor adherence, unlike the educational status. The major risk factors for non-adherence to medication reported in this study were busy at work or school, forgetfulness, fasting, and travelling away from home. These factors should be considered when designing and implementing adherence interventions. Patients' medicationtaking behaviors can be improved, and the optimal treatment outcomes could be achieved by targeting issues specific to the individual 
patient, enhancing the relationship between patients and health care providers, and helping patients understand the negative consequences of poor adherence. Intensive adherence counseling should be provided to all patients before initiation of antiretroviral therapy. Health care providers must identify possible barriers to adherence at the earliest and provide appropriate solutions.

Table 1. Distribution of the Socio-Demographic Characteristics of the Study Participants

\begin{tabular}{|c|c|c|c|c|}
\hline $\mathbf{S} / \mathbf{N}$ & Variables & Characteristics & Frequency & Percentage (\%) \\
\hline \multirow[t]{2}{*}{1} & \multirow[t]{2}{*}{ Gender } & Male & 253 & 63.3 \\
\hline & & Female & 147 & 36.7 \\
\hline \multirow[t]{3}{*}{2} & \multirow[t]{3}{*}{ Age } & $20-30$ & 65 & 16.3 \\
\hline & & $31-40$ & 192 & 48.0 \\
\hline & & $>40$ & 143 & 35.7 \\
\hline \multirow[t]{5}{*}{3} & \multirow[t]{5}{*}{ Educational Level } & Illiterate & 57 & 14.3 \\
\hline & & Islamic School & 11 & 2.7 \\
\hline & & Primary & 67 & 16.7 \\
\hline & & Secondary & 213 & 53.3 \\
\hline & & University and above & 47 & 11.7 \\
\hline \multirow[t]{3}{*}{4} & \multirow[t]{3}{*}{ Occupation } & Unemployed & 100 & 25.0 \\
\hline & & Self-Employed & 211 & 52.7 \\
\hline & & Employed & 89 & 22.3 \\
\hline \multirow[t]{4}{*}{5} & \multirow[t]{4}{*}{ Family Type } & Living alone & 133 & 33.3 \\
\hline & & Nuclear & 179 & 44.7 \\
\hline & & Extended & 57 & 14.3 \\
\hline & & Unknown & 31 & 7.7 \\
\hline \multirow[t]{2}{*}{6} & \multirow[t]{2}{*}{ Locality } & Rural & 135 & 33.7 \\
\hline & & Urban & 265 & 66.3 \\
\hline \multirow[t]{3}{*}{7} & \multirow[t]{3}{*}{ Distance from Clinic (Km) } & $50-200$ & 7 & 1.7 \\
\hline & & $200-400$ & 23 & 5.7 \\
\hline & & $>400$ & 370 & 92.6 \\
\hline
\end{tabular}

Table 2. Respondents' Responses to Medication Adherence

\begin{tabular}{|l|l|l|l|l|}
\hline S/N & Characteristics & Disagree (f/\%) & Neutral (f/\%) & Agree (f/\%) \\
\hline 1 & $\begin{array}{l}\text { Compared to other illnesses, HIV/AIDS } \\
\text { is NOT very serious }\end{array}$ & $320 / 80.0$ & $60 / 15.0$ & $20 / 5.0$ \\
\hline 2 & $\begin{array}{l}\text { If I do NOT take my HIV medications as } \\
\text { prescribed, I will become very sick }\end{array}$ & $20 / 5.0$ & $33 / 8.3$ & $347 / 86.7$ \\
\hline 3 & $\begin{array}{l}\text { If I take my HIV medications as } \\
\text { prescribed, I will still become very sick }\end{array}$ & $293 / 73.3$ & $93 / 23.3$ & $13 / 3.3$ \\
\hline 4 & $\begin{array}{l}\text { Taking HIV medications as prescribed } \\
\text { can prolong my life. }\end{array}$ & $13 / 3.3$ & $93 / 23.3$ & $293 / 73.3$ \\
\hline 5 & $\begin{array}{l}\text { Taking HIV medications interferes a } \\
\text { great deal with my normal activities. }\end{array}$ & $93 / 23.3$ & $200 / 50.0$ & $107 / 26.7$ \\
\hline
\end{tabular}




\begin{tabular}{|l|l|l|l|l|}
\hline 7 & $\begin{array}{l}\text { Taking HIV medications exactly as } \\
\text { prescribed decreases the chances of my } \\
\text { illness getting worse }\end{array}$ & $13 / 3.3$ & $27 / 6.7$ & $360 / 90.0$ \\
\hline 8 & $\begin{array}{l}\text { HIV medications cause annoying side } \\
\text { effects }\end{array}$ & $87 / 21.7$ & $213 / 53.3$ & $300 / 25.0$ \\
\hline 9 & $\begin{array}{l}\text { Taking HIV medications or having side } \\
\text { effects from them has made me feel more } \\
\text { nervous or depressed than usual. }\end{array}$ & $87 / 21.7$ & $187 / 46.7$ & $127 / 31.7$ \\
\hline 10 & $\begin{array}{l}\text { Dealing with the side effects of HIV } \\
\text { medications is stressful }\end{array}$ & $93 / 23.3$ & $173 / 43.3$ & $133 / 33.3$ \\
\hline 11 & $\begin{array}{l}\text { The HIV medications that I'm taking will } \\
\text { improve my health (i.e raise immune } \\
\text { system, cause weight gain, etc.). }\end{array}$ & $13 / 3.3$ & $93 / 23.3$ & $293 / 73.3$ \\
\hline 13 & $\begin{array}{l}\text { It is difficult to follow doctors' } \\
\text { instructions on HIV medications }\end{array}$ & $293 / 73.3$ & $0 / 0$ & $107 / 26.7$ \\
\hline
\end{tabular}

Table 3. Respondents' Reasons for Adherence to ARV (N=400)

\begin{tabular}{|l|l|l|l|}
\hline S/N & Characteristics & Frequency (N) & Percentage (\%) \\
\hline 1 & $\begin{array}{l}\text { Do you sometimes forget to take your [health concern] } \\
\text { pills? }\end{array}$ & 200 & 50.0 \\
\hline 2 & $\begin{array}{l}\text { Were there any days when you did not take your [health } \\
\text { concern] medicine? }\end{array}$ & 27 & 6.7 \\
\hline 3 & $\begin{array}{l}\text { Have you ever cut back or stopped taking your } \\
\text { medication without telling your doctor, because you felt } \\
\text { worse when you took it? }\end{array}$ & 373 & 93.3 \\
\hline 4 & $\begin{array}{l}\text { When you travel or leave home, do you sometimes forget } \\
\text { to bring along your [health concern] medication? }\end{array}$ & 227 & 56.7 \\
\hline 5 & Did you take your [health concern] medicine yesterday? & 400 & 100.0 \\
\hline 6 & $\begin{array}{l}\text { When you feel like your [health concern] is under } \\
\text { control, do you sometimes stop taking your medicine? }\end{array}$ & 20 & 5.0 \\
\hline 7 & $\begin{array}{l}\text { Taking medication every day is a real inconvenience for } \\
\text { some people. Do you ever feel hassled }\end{array}$ & 267 & 66.7 \\
\hline 8 & Are you careless at times about taking your medication & 13 & 3.3 \\
\hline 9 & $\begin{array}{l}\text { When you feel better, do you sometimes stop your } \\
\text { medication }\end{array}$ & 20 & 5.0 \\
\hline 10 & $\begin{array}{l}\text { Sometimes if you feel worse when you take the } \\
\text { medicine, do you stop taking it? }\end{array}$ & 27 & 6.7 \\
\hline 11 & Medication makes me feel tired and sluggish & 27 & 6.7 \\
\hline 12 & My thoughts are clearer on medication & 133 & 33.3 \\
\hline 13 & By staying on medication, I can prevent getting sick & 380 & 95.0 \\
\hline 14 & I feel weird, like a 'zombie', on medication & 387 & 96.7 \\
\hline
\end{tabular}




\section{Acknowledgements}

The author warmly appreciates all the participating patients and the management of Wuse District Hospital Abuja, FCT Nigeria.

\section{Authors Contribution}

O.A. and A.A. contributed to the conception and design of this study, O.A and R.B. performed the statistical analysis, O.A and O.R.

\section{References}

[1] Achappa B, Madi D, Bhaskaran U, Ramapuram JT, Rao S, Mahalingam S. Adherence to Antiretroviral Therapy Among People Living with HIV. N Am J Med Sci. 2013 Mar;5(3):220-3. doi: 10.4103/1947-2714.109196. PMID: 23626959; PMCID: PMC3632027.

[2] Paterson DL, Swindells S, Mohr J, Brester M, Vergis EN, Squier C, Wagener MM, Singh N. Adherence to protease inhibitor therapy and outcomes in patients with HIV infection. Annals of internal medicine. $2000 \mathrm{Jul}$ 4;133(1):21-30.

[3] Vrijens B, De Geest S, Hughes DA, Przemyslaw K, Demonceau J, Ruppar T, Dobbels F, Fargher E, Morrison V, Lewek P, Matyjaszczyk M. A new taxonomy for describing and defining adherence to medications. British journal of clinical pharmacology. 2012 May;73(5):691-705.

[4] Fong OW, Ho CF, Fung LY, et al. Determinants of adherence to highly active antiretroviral therapy (HAART) in Chinese HIV/AIDS patients. HIV Med 2003;4: 133-8.

[5] National AIDS Council. The Zambia HIV/AIDS Strategic Framework, 2 2021. Lusaka: Zambia Ministry of Health; 2016.

[6] Gupta M, Das SC. Determinants contributing for poor adherence to antiretroviral therapy: A hospital record-based study in Balasore, Odisha. J Family Med Prim Care. 2019 May;8(5):1720-1724. doi: 10.4103/jfmpc.jfmpc_40_19. PMID: 31198743; PMCID: PMC6559074.

[7] Mhaskar R, Alandikar V, Emmanuel P, Djulbegovic B, Patel S, Patel A. Adherence to antiretroviral therapy in India: A systematic review drafted the manuscript, O.A, R.B and O.R. critically reviewed the manuscript while A.A. supervised the whole study process. All the authors read and approved the final manuscript.

\section{Declaration of Conflicting Interests}

The author(s) declared no potential conflicts of interest with respect to the research, authorship, and/or publication of this article.

and analysis. Indian J Commun Med. 2013;38(2):7482. https://doi.org/10.4103/0970-0218.112435.

[8] Amelia J, Poquette DJ, Moore BG, Erin E, Morgan IG, Steven PW. Prospective memory and antiretroviral medication non-adherence in HIV: An analysis of ongoing task delay length using the memory for intentions screening test. $J$ Int Neuropsychol Soc. 2013; 19:155-161. https://doi.org/10.1017/S1355617712001051.

[9] Gast A, Mathes T. Medication adherence influencing factors an (updated) overview of systematic reviews. Systematic reviews. 2019 Dec;8(1):1-7.

[10]Schäfer C. Patientencompliance. Springer Fachmedien Wiesbaden; 2017.

[11] Peltzer K, Preez NF, Ramlagan S, Fomundam H, Anderson J, Chanetsa L. Antiretrovirals and the use of traditional, complementary and alternative medicine by HIV patients in Kwazulu-Natal, South Africa: A longitudinal study. Afr $J$ Tradit Complement Altern Med. 2011;8(4):337-345. https://doi.org/10.4314/ajtcam.v8i4.1.

[12] Kagee A, Remien RH, Berkman A, Hoffman S, Campos L, Swartz L. Structural barriers to ART adherence in Southern Africa: Challenges and potential ways forward. Global Public Health. 2011;6(1):83-97. https://doi.org/10.1080/17441691003796387.

[13] Masci JR. Outpatient management of HIV infection. 4th ed. Boka Raton, FL: CRC Press; 2011. [14] Coetzee B, Kagee A, Vermeulen N. Structural barriers to adherence to antiretroviral therapy in a resource-constrained setting: The perspectives of health care providers. AIDS Care. 2011;23(2):146151. https://doi.org/10.1080/09540121.2010.498874. 
[15] Ogbochi M, Naomi NM, Jerry WL, Peter CG, Gisele M. Determinants of antiretroviral therapy adherence among women in Southern Malawi: Healthcare providers' perspectives. AIDS Res Treatment.

https://doi.org/10.1155/2014/489370.

[16] Young S, Wheeler A, McCoy S, Weiser SD. A review of the role of food insecurity in adherence to care and treatment among adult and paediatric populations living with HIV and AIDS. AIDS Behav. 2014;18(5):505-515.

https://doi.org/10.1007/s10461-013-0547-4.

[17] Oku AO, Owoaje ET, Ige OK, Oyo-ita A. Prevalence and determinants of adherence to HAART amongst PLHIV in a tertiary health facility in southsouth Nigeria. BMC Infect Dis. 2013; 13:401.

[18] Basti BD, Mahesh V, Bant DD, Bathija GV. Factors affecting antiretroviral treatment adherence among people living with human immunodeficiency virus/acquired immunodeficiency syndrome: A prospective study. J Family Med Prim Care. 2017 Jul-Sep;6(3):482-486. doi: 10.4103/22494863.222014. PMID: 29416993; PMCID: PMC5787940.

[19] Ingersoll KS, Cohen J. The impact of medication regimen factors on adherence to chronic treatment: A review of literature. J Behav Med 2008; 31:213-24.

[20] Agu KA, Ochei UM, Oparah AC, and Onoh OU. Treatment outcomes in patients receiving combination ARV therapy in Central hospital, Benin City, Nigeria. Trop. J. Pharm. Res. 2010; 9: 1-10. [21] Schneider J, Kaplan SH, Greenfield S, Li W, Wilson IB. Better physician-patient relationships are associated with higher reported adherence to antiretroviral therapy in patients with HIV infection. Journal of General Internal Medicine. 2004; 19(11):1096-1103.

[22] Ammassari A, Trotta MP, Murri R, Castelli F, Narciso P, Noto P, Vecchiet J, Monforte AD, Wu AW, and Antinori A. Correlates and predictors of adherence to highly active antiretroviral therapy: overview of published literature. Journal of Acquired Immune Deficiency Syndromes 2002; 31(3): S123127.

[23] Murphy RL, Kivel NM, Zala C, Ochoa C, Tharnish P, Matthew J, et al. Antiviral activity and tolerability of amdoxovir with zidovudine in a randomized double-blind placebo-controlled study in HIV-1 infected individuals. Antivir Ther. 2010; 15:185-92.

[24] Möbius U, Lubach-Ruitman M, Castro-Frenzel B, Stoll M, Esser S, Voigt E, Christensen S, Rump JA, Fätkenheuer G, Behrens GM, Schmidt RE. Switching to atazanavir improves metabolic disorders in antiretroviral-experienced patients with severe hyperlipidemia. J Acquir Immune Defic Syndr. 2005 1;39(2):174-80. PMID: 15905733.

[25]Desai M, Iyer G, Dikshit RK. Antiretroviral drugs: critical issues and recent advances. Indian $J$ Pharmacol. 2012;44(3):288-298. doi:10.4103/02537613.96296.

[26] Johnson MO, Charlebois E, Morin SF, Catz SL, Goldstein RB, Remien RH, Rotheram-Borus MJ, Mickalian JD, Kittel L, Samimy-Muzaffar F, Lightfoot MA. Perceived adverse effects of antiretroviral therapy. Journal of pain and symptom management. 2005 1;29(2):193-205.

[27] World Health Organization. Rapid advice: Antiretroviral therapy for HIV infection in adults and adolescents. [Accessed on 2021 June]. Available from:

http://www.who.int/hiv/pub/arv/rapid_advice_art.pd f.

[28] De Maat MM, De Boer A, Koks CH, Mulder JW, Meenhorst PL, van Gorp EC, Mairuhu AT, Huitema $\mathrm{AD}$, Beijnen JH. Evaluation of clinical pharmacist interventions on drug interactions in outpatient pharmaceutical HIV-care. Journal of clinical pharmacy and therapeutics. 2004, 29(2):121-30. 